\title{
Control of Panama disease of banana by intercropping with Chinese chive (Allium tuberosum Rottler): cultivar differences
}

\author{
Zhenfang Li, Tong Wang, Chenling He, Kelin Cheng, Rensen Zeng and Yuanyuan Song*
}

\begin{abstract}
Panama disease (Fusarium wilt disease) caused by Fusarium oxysporum f. sp. cubense race 4 (FOC) severely threatens banana (Musa spp.) production worldwide. Intercropping of banana with Allium plants has shown a potential to reduce Panama disease. In this study, six cultivars of Chinese chive (Allium tuberosum Rottler) were selected to compare their differences in antifungal activity and active compounds. Three cultivars Duokang Fujiu 11, Fujiuhuang 2, and Duokang Sijiqing with higher levels of antifungal compounds were further used for intercropping with banana in the pots and field to compare their effects on growth and disease incidence of banana.

The six cultivars showed significant differences in antifungal activity against FOC mycelia growth in both leaf volatiles and aqueous leachates. The aqueous leachates displayed stronger antifungal activity than the volatiles. FJH cultivar showed the best inhibitory effect among all six cultivars. Contents of three main antifungal compounds dipropyl trisulfide (DPT), dimethyl trisulfide (DMT), and 2-methyl-2-pentenal (MP) in volatiles and aqueous leachates varied considerably among cultivars. Pot and field experiments showed that intercropping with three selected Chinese chive cultivars significantly improved banana vegetative growth, increased photosynthetic characteristics and yield but decreased disease incidence of Panama disease.

Our results indicate that intercropping with Chinese chive shows potential to reduce banana Panama disease and selection of appropriate cultivars is vital for effective disease control.
\end{abstract}

Keywords: Banana, Fusarium wilt disease, Chinese chive, Intercropping, 2-Methyl-2-pentenal, Cultivar

\section{Background}

Banana (Musa spp.) is one of the world's most important crops and it serves as a staple food in many developing tropical and subtropical countries [1]. It ranks next to rice, wheat, and maize in terms of its importance as a staple food crop [2]. Over 100 million metric tons of the crop are produced annually [3]. However, this crop production is severely hampered by Panama disease (also known as Fusarium wilt disease) caused by Fusarium

\footnotetext{
* Correspondence: yyuansong@163.com

Key Laboratory of Ministry of Education for Genetics, Breeding and Multiple Utilization of Crops, College of Agriculture, Fujian Agriculture and Forestry University, Fuzhou 350002, China
}

oxysporum f. sp. cubense race 4 (FOC) [4], leading to extensive failure of commercial plantations in all bananaproducing areas, including Asia, Central and South America, Africa, and Australia [5-7]. The soil-borne fungal pathogen colonizes and occludes the host xylem to cause vascular wilt $[5,6,8]$. So far not yet a practically effective approach of controlling this notorious disease in the field is available. Soil sterilization using fungicides has been used only for intensive agriculture in greenhouses on a limited scale $[9,10]$. Environmentally friendly cultural practices and fungicides are urgently needed [11-13]. Fungicides are not able effectively to control this soil-borne pathogen in the field, for a variety

(c) The Author(s). 2020 Open Access This article is licensed under a Creative Commons Attribution 4.0 International License, which permits use, sharing, adaptation, distribution and reproduction in any medium or format, as long as you give appropriate credit to the original author(s) and the source, provide a link to the Creative Commons licence, and indicate if changes were made. The images or other third party material in this article are included in the article's Creative Commons licence, unless indicated otherwise in a credit line to the material. If material is not included in the article's Creative Commons licence and your intended use is not permitted by statutory regulation or exceeds the permitted use, you will need to obtain permission directly from the copyright holder. To view a copy of this licence, visit http://creativecommons.org/licenses/by/4.0/ The Creative Commons Public Domain Dedication waiver (http://creativecommons.org/publicdomain/zero/1.0/) applies to the data made available in this article, unless otherwise stated in a credit line to the data. 
of ecological reasons [14]. Nowadays, cultural practices have been tried with little success, for there has not been a suitably productive cultivar to selection or breeding for reducing the incidence of diseases caused by FOC [15]. Recently, crop rotation and microorganisms have shown promise for reducing the disease severity $[16,17]$.

Chinese farmers have practiced intercropping and rotation for disease control over 2000 years [18, 19]. Intercropping, which is defined as the growing of two or more crop species in proximity simultaneously during a growing season, is an agricultural practice that not only increases crop yield and stress resilience, but also reduces the incidence of microbial diseases. Chemicals produced by one plant in the intercropping system, can either directly inhibit microbial pathogens in the soils, or indirectly trigger resistance through the induction of the plant defense system in neighboring plants $[20,21]$. The Allium plants are characterized with the production of many antimicrobial substances [21-24]. They are among the oldest medicinal herbs, used as antibacterial, antifungal, antioxidant and cytotoxic drugs [25]. In addition to many organosulphur compounds, mainly disulphides and trisulphides, Allium plants also produce non-volatile compounds such as spirostanol, furostanol and cholesterol saponin with antimicrobial, antifungal, antiplatelet aggregating, and cytotoxic activities [26-30]. Many Allium species such as garlic, onion and Chinese chive ( $A l$ lium tuberosum) are widely cultivated for their spice and medicinal properties. Chinese chive is an important vegetable for making dumpling and kimchi in many Asian countries such as China and Korea. Chinese chive is now gaining increasing attention due to its diverse important pharmacological activities [28, 31]. Although many studies have been conducted for food and pharmacological purposes [24, 32], Allium plants as biological control agents for crop disease in the intercropping system and underlying mechanisms are scarcely addressed [33, 34]. The sequential cropping systems are becoming increasingly popular in all management practices for their environmental friendliness.

Recent studies indicated that banana intercropping with Chinese chive could effectively control Fusarium wilt of banana [31, 34, 35]. Our previous study showed that Chinese chive exhibited strong inhibitory effects on FOC through the release of organic volatiles, among which 2-methyl-2-pentenal, dimethyl trisulfide, dimethyl disulfide, dipropyl disulfide, and dipropyl trisulfide are the main active antifungal compounds [34]. However, crop varieties may markedly differ in their ability to produce antimicrobial chemicals [36].

In this paper, we selected six Chinese chive cultivars with obviously morphological difference and distinct characteristics to compare their antifungal activity against FOC and active compounds in the leaf volatiles and aqueous leachates of aerial parts. Three cultivars with higher contents of three antifungal compounds including dipropyl trisulfide (DPT), dimethyl trisulfide (DMT), 2methyl-2-pentenal (MP) in the volatiles or aqueous leachates were further used in pot experiments to evaluate their potential in reducing disease incidence of Fusarium wilt disease of banana.

\section{Methods}

\section{Chemicals}

Three antifungal compounds including dipropyl trisulfide (DPT), dimethyl trisulfide (DMT), and 2-methyl-2pentenal (MP) were obtained from Sigma-Aldrich (St. Louis, MO, USA). All solvents used were analytical or HPLC grade.

\section{Plant materials}

The banana plant in this study was "Williams" (AAA genome, Cavendish subgroup) banana cultivar, which was purchased from Tianyang banana breeding Co. in Guangxi province in China, is highly susceptible to $F$. oxysporum f. sp. cubense race 4 (Warman, 2018).

The seeds for the six Chinese chive cultivars were purchased from Fusheng seed Co. in Henan province in China and were preserved in our laboratory. The sampling on the materials were conducted on our experimental field in Fujian Agriculture and Forestry University in Fujian province. The cultivar Duokang Fujiu 11 (DKF) shows strong resistance to stress and a strong special spicy odor. The Fujiubao (FJB) shows the strongest spicy odor among the six varieties but the lowest stress resistance. The Fujiuhuang $2(\mathrm{FJH})$ shows a moderate spicy odor and stress resistance, its leaves are yellow (the rest were green). The Duokang Sijiqing (DKS) shows high resistance but almost no spicy odor. The Futaijiu 1 (FTJ) shows strong spicy odor but weak resistance and garlic sprout. The Zigenchun Zaohong (ZGC) shows a medium level of stress resistance and spicy odor but red roots (roots of the rest are white).

\section{FOC fungal materials}

The original fungal inocula of $F$. oxysporum f. sp. cubense race 4 (FOC) were kindly provided by Professor Zide Jiang of College of Agriculture at South China Agricultural University in Guangzhou [34]. The strain was maintained in Potato Dextrose Agar (PDA), and the inocula were cultured in PDA at $25^{\circ} \mathrm{C}$ in darkness. PDA medium was prepared and sterilized by autoclaving at $121^{\circ} \mathrm{C}$ for 20 min [5].

The FOC conidial suspension was prepared by incubating FOC in PDA broth on a shaker at $200 \mathrm{rpm}$ and $28^{\circ} \mathrm{C}$ for 5 days, followed by filtration with two layers of gauze to remove the mycelia. The conidial concentration was adjusted to $1 \times 10^{6}$ conidia per milliliter [37]. 


\section{Inhibitory effect of leaf volatiles}

To compare the inhibitory effect of the volatiles from the six Chinese chive cultivars, fresh leaves of six Chinese chive cultivars were cut into segments (about $1 \mathrm{~cm}$ long and $0.4 \mathrm{~cm}$ wide) or ground into powder in liquid nitrogen, respectively. Then the leaves were added in a fourroom petri dish ( $90 \mathrm{~mm}$ in diameter) and inoculated with two $4 \mathrm{~mm}$ discs of FOC inocula. The mass of leaves was $0.6 \mathrm{~g}$ FW in the petri dish. Similar petri dish without Chinese chive leaves was used as controls. Six replicates were prepared for each treatment. Each six-petri dish containing the same sample were placed in the middle of a $4000 \mathrm{ml}$ glass jar (the height and the diameters of top and bottom were $12.5,22$, and $19 \mathrm{~cm}$, respectively).

The experiment was conducted in a climate-controlled room at $25^{\circ} \mathrm{C}$ in darkness. Colony diameters of the inoculated FOC were measured with a Vernier caliper when the colony of the control had reached the peripheral wall.

\section{Inhibitory effect of aqueous leachates of the aerial parts}

To examine the inhibitory effect of aqueous leachates of the six Chinese chive cultivars on FOC colony growth, the fresh aerial parts $(50 \mathrm{~g})$ were also ground into powder in liquid nitrogen and soaked in $100 \mathrm{~mL}$ distilled water at $25^{\circ} \mathrm{C}$ for $20 \mathrm{~min}$ for extractions by an ultrasonic agitation, respectively (Zuo et al. 2016). Then, the aqueous solution was centrifuged at $10000 \mathrm{rpm}$ for $5 \mathrm{~min}$. After centrifugation, the supernatant was filtered first through normal filter paper $(0.45 \mu \mathrm{m}$, Xingya Purification Factory, Shanghai, China) and then through a microfilter of pore size $0.22 \mu \mathrm{m}$ (Whatman puradiscTM25AS polyethersulfone membrane, catalog NO.67942514, England). The final filtrate was our original leachates with a concentration of $0.5 \mathrm{~g} \mathrm{FW} \cdot \mathrm{mL}^{-1}$.

The filtered leachates $(5 \mathrm{~mL})$ of each cultivar and fungal culture medium $(5 \mathrm{~mL})$ were mixed and added in petri dishes (90 $\mathrm{mm}$ in diameter) and inoculated with a $4 \mathrm{~mm}$ discs of FOC. The concentration of final culture medium was $0.25 \mathrm{~g} \mathrm{FW} \cdot \mathrm{mL}^{-1}$. Similar petri dish without Chinese chive leachate but with the same volume of distilled water was used as controls. Six replicates were prepared for each treatment.

The experiment was conducted as described in the above methods part 'Inhibitory effect of leaf volatiles'.

\section{Antifungal activities of DPT, DMT and MP}

Based on our previous result, three compounds including DPT, DMT, and MP were used to test the antifungal activities against FOC colony growth. Four beakers (250 $\mathrm{mL}, 75 \mathrm{~mm}$ in diameter) filled with $10 \mathrm{~mL}$ fungal culture medium of PDA were placed in a $4000 \mathrm{~mL}$ glass jar (the height and the diameters of top and bottom were 12.5 , 22 , and $19 \mathrm{~cm}$, respectively), and inoculated with $4 \mathrm{~mm}$ disc of FOC. A piece of degreasing cotton filled with
$100 \mu \mathrm{L}$ the antifungal compounds (DPT, DMT, and MP) was placed in the middle of the jar. The final concentration of the three compounds was $25 \mu \mathrm{L} \cdot \mathrm{L}^{-1}$. Similar beakers in each glass jar without antifungal compound were used as controls. The glass jars were covered carefully with two layers of cellophane to stop the volatiles from escaping the [38]. Five replicates were prepared for each treatment. Thus, each treatment had 20 beakers placed in 5 glass jars.

The experiment was conducted in an incubator at $25^{\circ} \mathrm{C}$. Colony diameters of the inoculated FOC were measured with a ruler from the bottom by placing the glass jar on a high platform starting from $48 \mathrm{~h}$ post inoculation until 5 days when the colony of the control (no antifungal compound) breakers had grown close to the peripheral wall.

\section{Quantification of DPT, DMT and MP in the volatiles or aqueous leachates}

To quantify DPT, DMT and MP in the volatiles released from Chinese chive cultivars, the volatiles were trapped according to the methods described by Zhang et al. [34]. The leaves of Chinese chives $(150 \mathrm{~g})$ were cut with $1 \mathrm{~cm}$ segments and added into a $500 \mathrm{~mL}$ flask. The volatiles were trapped through a glass tube ( $3 \mathrm{~mm}$ inner diam, 14 $\mathrm{cm}$ long) packed with $150 \mathrm{mg}$ of Tenax TA (2.6-diphenylene oxide polymer resin) for $5 \mathrm{~h}$. Trapped volatiles were eluted from each tube with $1 \mathrm{~mL} n$-hexane and then were used for analysis by a gas chromatography system (GC) as described by Nandakumar et al. [38].

To quantify DPT, DMT and MP in the aqueous leachates of Chinese chive cultivars, the leaves $(50 \mathrm{~g})$ were ground into powder in liquid nitrogen and extracted with $100 \mathrm{~mL}$ distilled water at $25^{\circ} \mathrm{C}$ for $20 \mathrm{~min}$ through an ultrasonic agitation, respectively. Then aqueous solution was centrifuged at $10000 \mathrm{rpm}$ for $5 \mathrm{~min}$. The supernatant $(60 \mathrm{~mL})$ was consecutively partitioned with dichloromethane $(100 \mathrm{~mL})$. The dichloromethane layer was separated with a separatory funnel, followed by evaporation under vacuum. The substance of dichloromethane phase was finally dissolved with dichloromethane to $5 \mathrm{~mL}$. The final solution was filtrated by a micro filter with pore size $0.22 \mu \mathrm{m}$ for and ready for GC analyses.

GC analyses were performed on an Agilent GC 7890B system (Agilent Technologies, Palo Alto, CA, USA) with a flame ionization detector (FID) and a capillary column Agilent 19,091 J-413 HP-5 (5\% phenylmethyl siloxane, $30.0 \mathrm{~m} \times 320 \mu \mathrm{m} \times 0.25 \mu \mathrm{m})$. The injection temperature was $150^{\circ} \mathrm{C}$, and the oven temperature was raised from $35^{\circ} \mathrm{C}$ ( 2 min hold) to $250^{\circ} \mathrm{C}$ at a rate of $10^{\circ} \mathrm{C} \cdot \mathrm{min}^{-1}$. Two microliters of sample were injected, and nitrogen was used as the carrier gas at a flow rate of $1.0 \mathrm{~mL} \cdot \mathrm{min}^{-1}$.

\section{Banana intercropping with three Chinese chive cultivars in the pots}

Based on the results of antifungal activities and quantity of the three active compounds, three cultivars $(\mathrm{FJH}$, 
DKS, and DKF) of Chinese chive were selected to intercrop with banana in pots (the height and the diameters were 34 and $40 \mathrm{~cm}$ ) filled with soils from the field of monoculture banana plantation for 6 years in Moxi Village, Tianbao Town of Nanjing County, Fujian Province

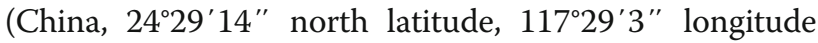
east). The monoculture banana in the same soil served as a control (CK). Thirty days after intercropping with Chinese chive under greenhouse conditions $\left(25 \pm 4{ }^{\circ} \mathrm{C}\right.$; $16 / 8 \mathrm{~h} \mathrm{light/dark}$ photoperiod), each pot of all treatments (including CK treatment) was watered with 100 $\mathrm{ml}$ Fusarium conidial suspension $\left(1 \times 10^{6}\right.$ spores $\left.\mathrm{mL}^{-1}\right)$ prepared as described above. The treatments and controls consisted of 10 plants per replicate.

Sixty days after fungal inoculation, plant height, stem circumference, photosynthesis parameters and disease indices were recorded. Net photosynthetic rate and stomatal conductance of the bananas were measured with Li-6400 (LI-COR, Lincoln, NE, USA). At the end of the experiment, each plant was harvested to assess the disease indices [39].

\section{Banana intercropping with three Chinese chive cultivars in the field}

Seeds of three Chinese chive cultivars (FJH, DKS, and DKF) were sown in an experimental field in Moxi Village, Tianbao Town of Nanjing County, Fujian Province (China), in March of 2016 for 10 months planting. An experimental field that Fusarium wilt disease frequentlyoccurred in the village in January of 2017 was selected and divided into 20 plots each with a size of $2.5 \times 25 \mathrm{~m}^{2}$ ([21]; Huang et al., 2016). Among the 20 plots, 5 plots were mono-cultured with banana plants (CK), and in the other 15 plots, banana plants were intercropped with the Chinese chive cultivars (FJH, DKS, and DKF) that had planted for 10 months at a spacing of $15 \times 10 \mathrm{~cm}^{2}$. Five plots from another field nearby with no fusarium wilts disease occurred were also mono-cultured with banana plants (mock). Each plot of all treatments was planted with ten plants (at a spacing of $2.5 \times 2.25 \mathrm{~m}^{2}$ ) of banana cultivar "Williams". The planting site was prepared and managed using established cultivation practices, without the application of either herbicide or fungicides. Plants were fertilized twice a year by using NPK $\left(\mathrm{N}: \mathrm{P}_{2} \mathrm{O}_{5}\right.$ : $\mathrm{KCL}=10: 3: 2)$ with dose of $3 \mathrm{~kg} \cdot$ plot $^{-1}$. The incidence of Fusarium wilt disease of banana was examined every 30 days. When the banana ripened, fruit weight of each plant was weighed.

\section{Statistical analysis}

Antifungal activities of three antifungal compounds, inhibitory effect of volatiles or aqueous leachates of the six Chinese chive cultivars on FOC were presented as inhibition rate (\%) compared to control using the following formula: inhibition rate $(\%)=[$ (colony diameters of control - colony diameters of treatment) / colony diameters of control] $\times 100$.

All data were subjected to analysis of variance using the Statistical Analysis System Program (SPSS 9.0). Each value was expressed as the mean \pm the standard error (SE). Statistical significance was analyzed using Student's $t$-test and one-way analysis of variance (ANOVA). The precision of the method was confirmed by leastsignificant difference (LSD, \%). The values were considered significant when the $P$ value was $<0.05$.

\section{Results}

Inhibitory effect of volatiles from the six cultivars

Fresh leaves of the six Chinese chive cultivars were treated in two ways: cut into $1 \mathrm{~cm}$ segments to acquire the naturally released volatiles, or ground into powder in liquid nitrogen to acquire maximally released volatiles. Bioassays showed that both the sliced leaves treatment and the ground-leaves treatment strongly inhibited the mycelial growth of FOC (Fig. 1).

In the sliced leaves treatment, the volatiles from all the six Chinese chive cultivars significantly inhibited mycelial growth of FOC (Fig. 1a). FJH cultivar with yellow leaves displayed the maximum inhibition (61\%), which was much higher than the other five cultivars. The DKS and ZGC showed 25 and $22 \%$ inhibition, respectively. The other three cultivars showed marginal inhibitory effect $(\leq 12 \%)$.

In the ground-leaves treatment, the inhibitory effect of volatiles of all cultivars was much higher than that in sliced leaves treatments (Fig. 1b). Three cultivars $(\mathrm{FJH}$, ZGC and DKS) displayed 60-62\% inhibition against FOC mycelia growth, which were significantly higher than the other three cultivars.

Inhibitory effects of aqueous leachates of the six cultivars The FOC colony growth in the presence of aqueous leachates of six Chinese chive cultivars is shown in Fig. 2. The aqueous leachates exhibited significant higher inhibitory effects (inhibition rate ranging from 55 to $72 \%$ ) on FOC colony growth than the volatiles. The largest antifungal effect $(72 \%)$ was obtained from the Chinese chive cultivar DKS, followed by FJH and DKF with inhibition of 68 and 67\%, respectively (Fig. 2).

\section{Antifungal activity of DPT, DMT and MP}

2-Methyl-2-pentenal (MP), dimethyl trisulfide (DMT) and dipropyl trisulfide (DPT) identified from Chinese chive significantly inhibited mycelial growth of FOC at a concentration of $25 \mu \mathrm{L} \cdot \mathrm{L}^{-1}$ (Fig. 3). MP almost completely inhibited the mycelial growth (99\% inhibition), while DPT and DMT showed approximate 30\% inhibition. 


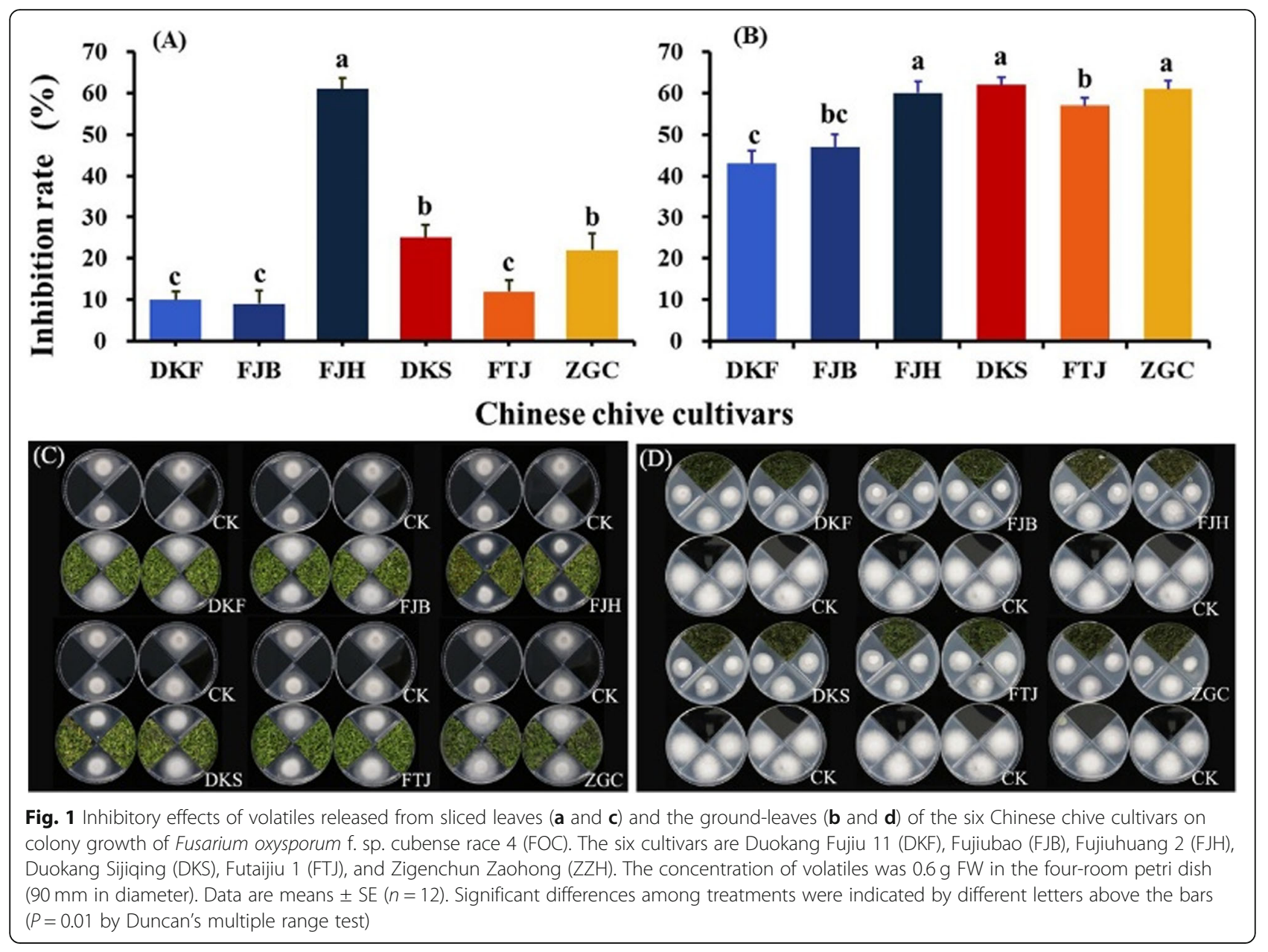

Contents of MP, DMT and DPT in the six cultivars

Since MP, DMT and DPT are important antifungal compounds in Chinese chive, and different chive species exhibited inconsistent inhibitory effect, we speculated that difference in antifungal activities among the six cultivars resulted from their difference in concentrations of DPT, DMT and MP. We, therefore, detected the contents of MP, DMT and DPT (Fig. 4) in the volatiles and aqueous leachates of the six Chinese chive cultivars.

The contents of MP, DMT and DPT significantly differed among the six Chinese chive cultivars. The highest concentrations of MP, the most active antiFOC compound, was found in the cultivar FJH in both volatiles and leachates. The second most abundant MP was found in the volatiles of the cultivar ZGC and in the leachates of the cultivar DKS. DKS contained relative higher DPT, DMT and MP contents among all six chive species, while FJB and FTJ contained relative lower contents of these three antifungal substances (Fig. 4). For example, the content

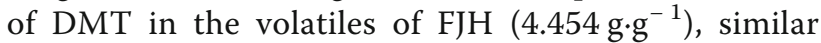
to that in DKS, was nearly two times as the content in FJB $\left(2.282 \mu \mathrm{g} \cdot \mathrm{g}^{-1}\right)$. This might explain that FJH and DKS had better performances in antifungal assays. Although DKF released less DMT and DPT than ZGC in aqueous leachates (Fig. 4), its anti-FOC activity was high, which might result from the higher contents of MP in aqueous leachates of DKF (0.794 $\left.\mathrm{g} \cdot \mathrm{g}^{-1}\right)$ that was significantly higher than ZGC $(0.253$ g.g ${ }^{-1}$ ) (Fig. 4).

\section{Intercropping improved banana growth and} photosynthesis in the pots

Based on antifungal activity against FOC, three Chinese chive cultivars DKF, FJH and DKS with higher contents of DPT, DMT and MP, were selected for intercropping with banana in pot experiment to examine their differential effects on Panama disease.

Ninety days after intercropping with Chinese chive, plant heights of banana plants were significantly improved by all three cultivars relative to monoculture control. Stem diameters were significantly improved by intercropping with FJH and DKS (Fig. 5). 

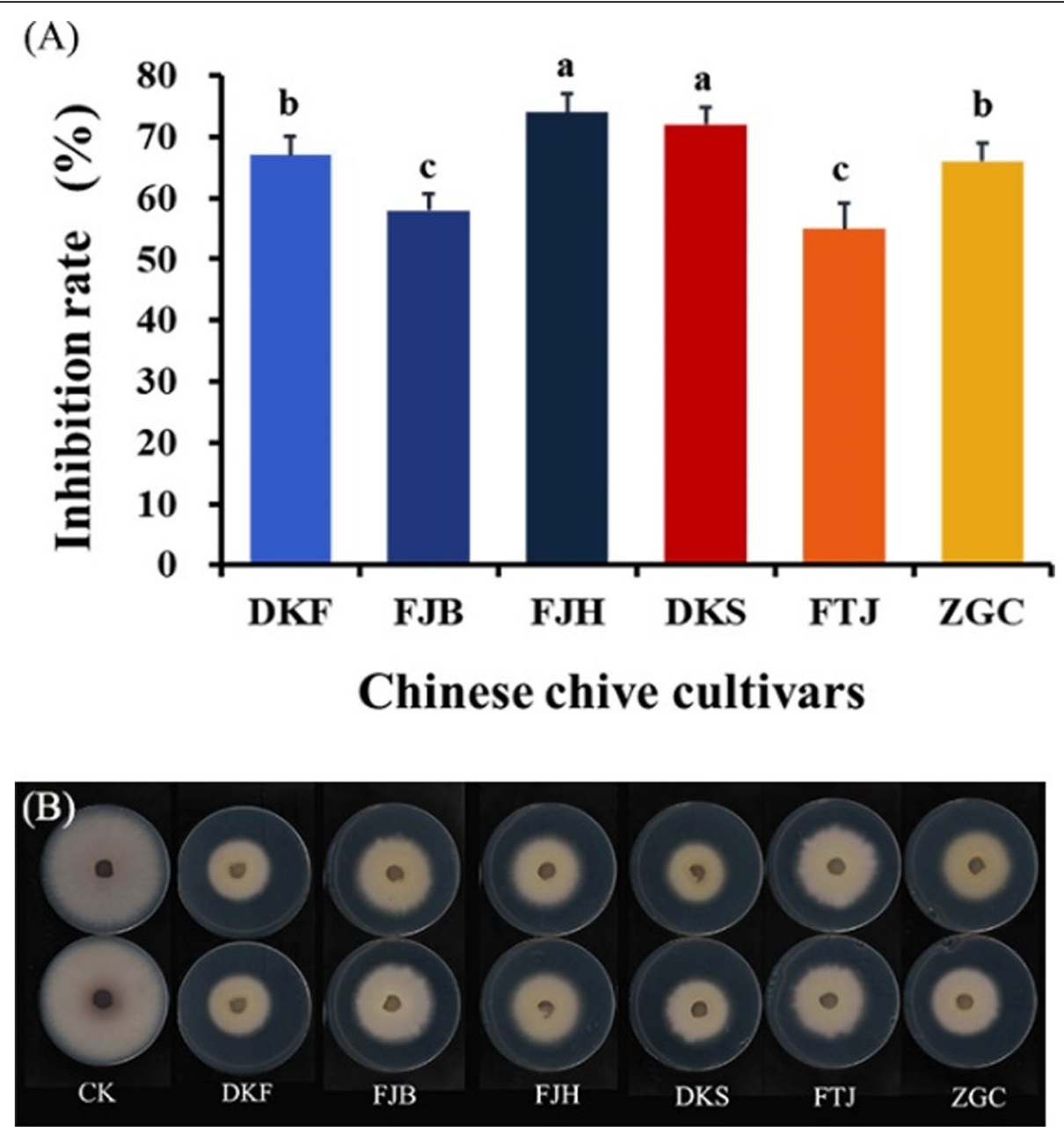

Fig. 2 Statistical results (a) and petri dish exhibition (b) of inhibitory effects of aqueous leachates of aerial parts of six Chinese chive on colony growth of Fusarium oxysporum f. sp. cubense race 4 (FOC). The six cultivars were Futaijiu 1 (FTJ), Fujiubao (FJB), Fujiuhuang 2 (FJH), Duokang Sijiqing (DKS), Duokang Fujiu 11 (DKF) and Zigenchun Zaohong (ZGC). The concentration of aqueous leachates was $0.25 \mathrm{~g} \mathrm{FW} \cdot \mathrm{mL}^{-1}$. Data are means \pm SE $(n=6)$. Significant differences among treatments were indicated by different letters above the bars $(P=0.01$ by Duncan's multiple range test)

As shown in Fig. 6, the photosynthetic characteristics of banana functional leaves including net photosynthetic rate $(P n)$, stomatal conductance $(G s)$, and transpiration rate $(T r)$ in intercropping system were significantly higher than those in the monoculture system. Obviously, intercropping with all three cultivars significantly improved net photosynthetic rate and stomatal conductance of banana plants, but reduced intercellular $\mathrm{CO}_{2}$ concentration relative to monoculture banana plants (Fig. 6). Intercropping with FJH and DKS also significantly enhanced transpiration rate. Intercropping with DKF did not have obvious effect on transpiration rate. Furthermore, the cultivar FJH showed the strongest effects on the four photosynthetic parameters in the intercropping system.
Intercropping reduced the Fusarium wilt incidence of banana in the pots

The occurrence of Panama disease of banana was significantly reduced after intercropping with all three cultivars of Chinese chive relative to monoculture banana plants (Fig. 7a). Intercropping with FJH, DKS and DKF reduced the disease indices by $65.7,62.8$ and $29.8 \%$, respectively. The lowest disease indices (Fig. 7a) and very few yellow leaf symptoms were found in the banana plants intercropping with $\mathrm{FJH}$.

Intercropping reduced the Fusarium wilt disease incidence but increased banana yield in the field Field experiments were conducted in 2017 and 2018 to evaluate the effects of intercropping with the three selected Chinese chive cultivars on banana resistance to 

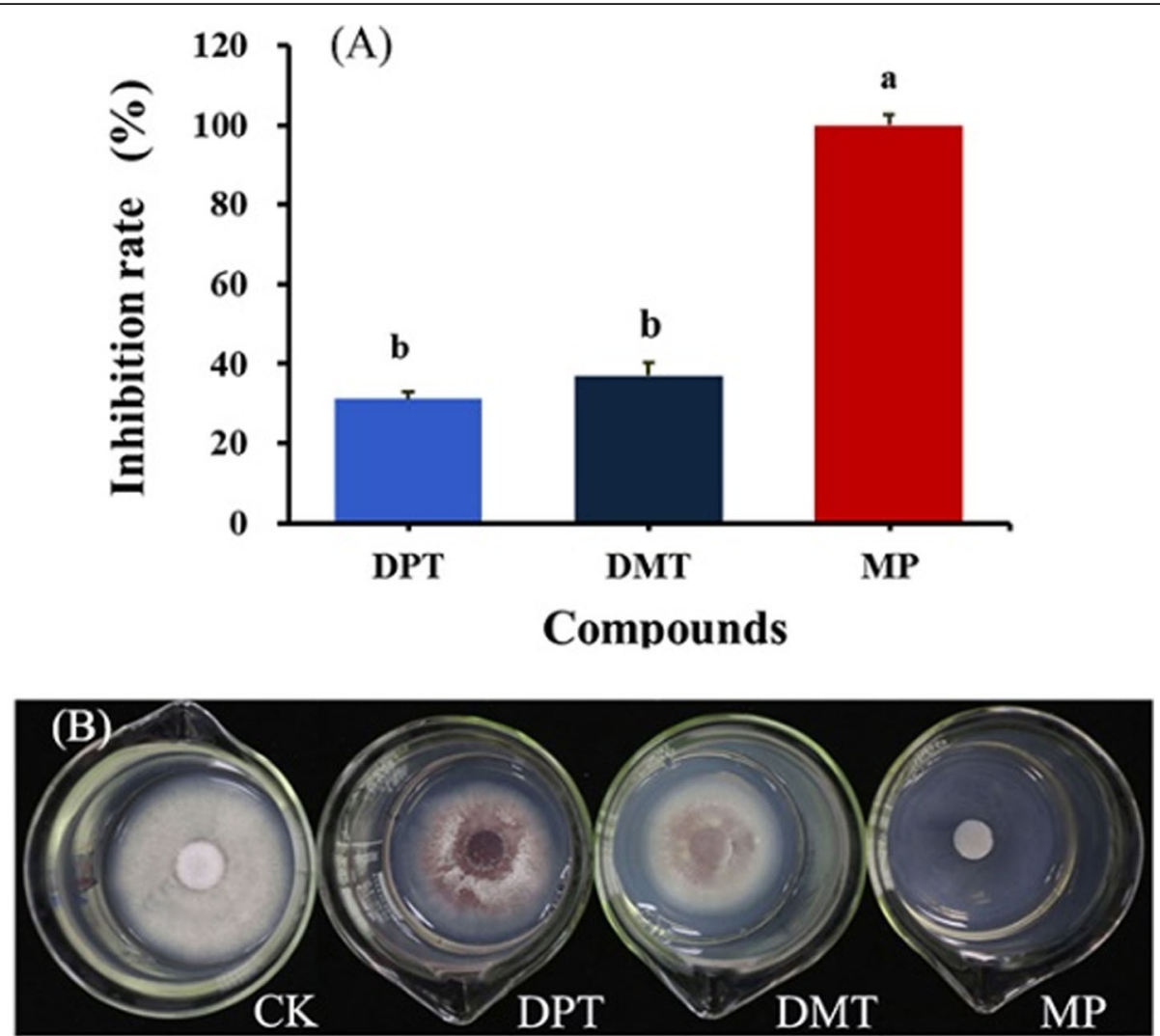

Fig. 3 Statistical results (a) and experiment results exhibition (b) of antifungal activity of three compounds identified from Chinese chive against colony growth of Fusarium oxysporum f. sp. cubense race 4 (FOC). The final concentration of the three compounds, 2-methyl-2-pentenal (MP), dimethyl trisulfide (DMT) and dipropyl trisulfide (DPT) was $25 \mu \mathrm{L} \cdot \mathrm{L}^{-1}$. Data are means $\pm \mathrm{SE}(n=20)$. Significant differences among treatments were indicated by different letters above the bars ( $P=0.01$ by Duncan's multiple range test)

Fusarium wilt, as well as fruit weight per plant and yield (Fig. 8). Intercropping with all three Chinese chives cultivars significantly reduced the disease incidence but increased banana yield in comparison with the monoculture control (Fig. 8a \& c). The lowest disease incidence and highest yield were found in banana plants intercropping with the cultivar Fujiuhuang 2 (FJH), followed by the cultivar DKS in both 2017 and 2018 . Intercropping with $\mathrm{FJH}$ and DKS increased the yield by 5.04- and 2.78-fold, respectively (Fig. 8c). Intercropping with DKF displayed the weakest effect on both banana disease incidence and yield. However, the intercropping with FJH and DKS showed no obvious effects on fresh weight of each plant (Fig. 8b). Only DKF displayed a bit negative effect on fresh weight of each plant.

\section{Discussion}

Panama disease severely affects banana production worldwide. Appropriate agricultural practices show potentials to successfully minimize the detrimental effect of the disease [9, 10, 40,41]. Rotation and intercropping with Chinese chive have been demonstrated to be effective approaches to control the disease at both greenhouse and field levels [31, 34, 35]. This study showed that the cultivar selection is a key factor for successful control of the disease. Although all cultivars displayed obvious inhibition to the disease in both greenhouse and field conditions (Figs. $7 \&$ 8), they showed significant difference in their ability to reduce the disease incidence. Two cultivars FJH and DKS exhibited much stronger inhibition against Panama disease. In particular, the cultivar $\mathrm{FJH}$ showed the highest inhibition to the disease and best improvement for the banana yield in both pot and field experiments (Figs. 7 \& 8). Interestingly, in laboratory both volatiles and aqueous leachates of FJH showed the strongest inhibitory effect on the pathogen FOC among the six cultivars tested (Figs. 1 \& 2). Meanwhile, the cultivar $\mathrm{FJH}$ produced the highest amount of 2methyl-2-pentenal in both volatiles and aqueous leachates (Fig. 4a \& b), which showed the strongest antifungal activity against FOC (Fig. 3 [34];). All results from laboratory, greenhouse and field experiments suggested that the cultivar FJH is the best cultivar of Chinese chive for intercropping with banana to control Panama disease. The 


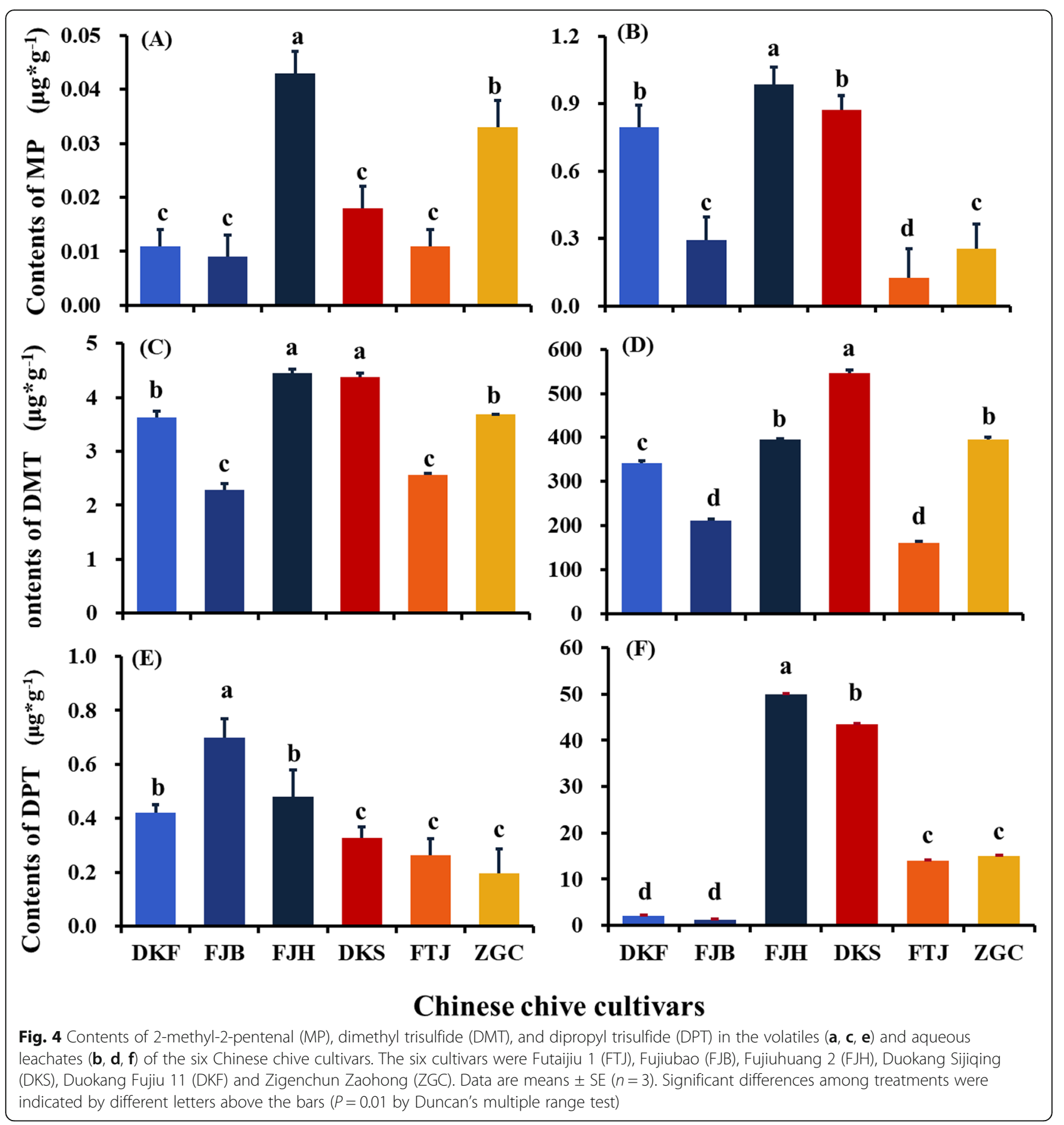

second better cultivar is DKS, which produced the second abundant 2-methyl-2-pentenal in the aqueous leachate (Fig. 4b), and showed the second strongest antifungal activity against FOC in the leachate (Fig. 2). Schulz et al. [42] revealed the influence of the genetic background of the parent cultivars on the sulfur volatile composition in the Allium hybrid. Therefore, selection of appropriate cultivars of Chinese chive with strong anti-FOC activity for intercropping is a key for successful control of Panama disease. More cultivars should be screened to find suitable ones for intercropping with banana.

Volatile compounds released from host plants play an important role in plant defense against microbial pathogens [43]. Allium species are well-known to produce many volatile organosulfur compounds, which contribute to the unique smell and taste of these plant species $[38,44]$. These compounds exhibit broad-spectrum biological activities towards 


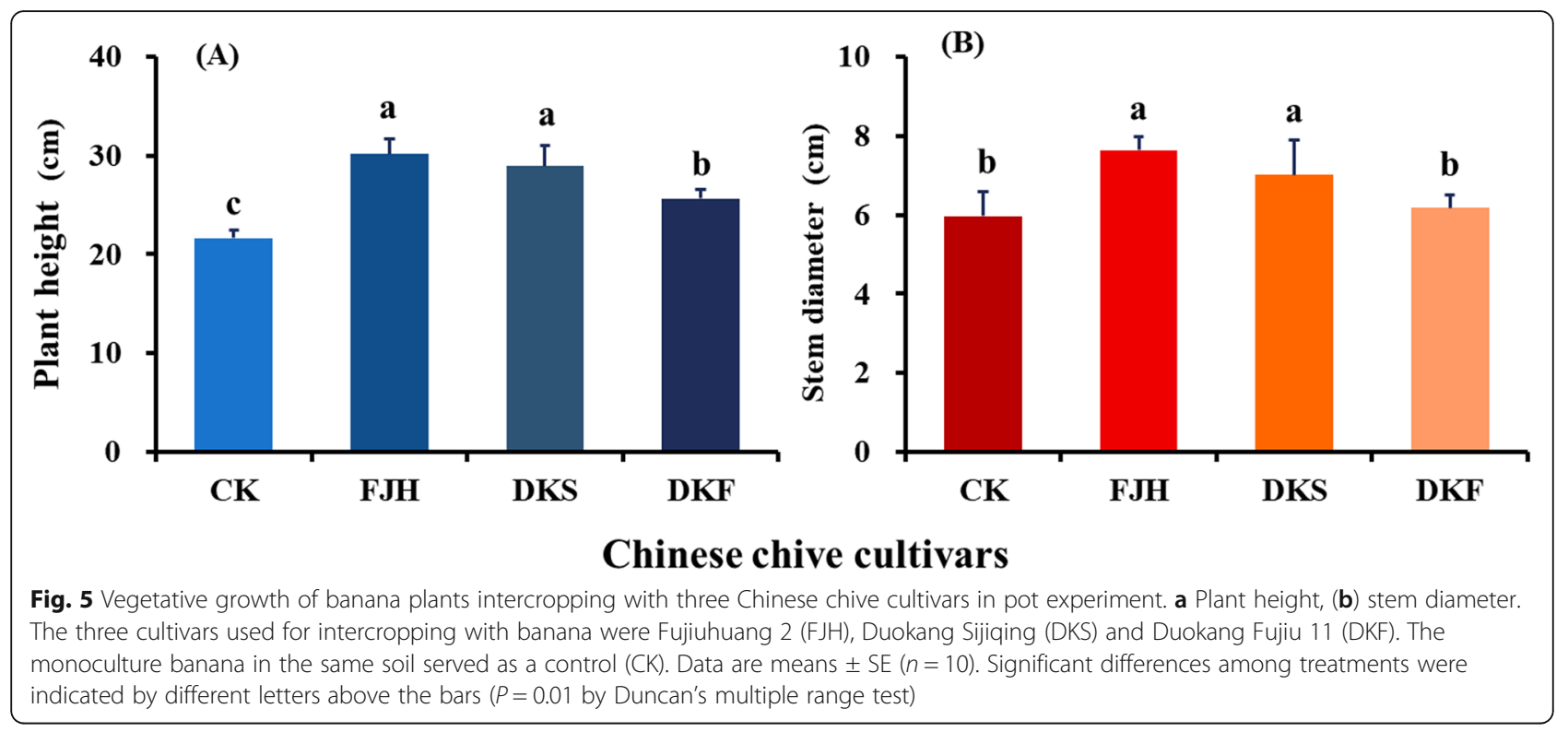

microorganisms, plants and animals [44, 45]. Although this study showed that aqueous leachates displayed much higher anti-FOC activity, the active compounds in the aqueous leachates were volatiles and low polarity [34, 46], which is consistent with the result that the aqueous leachates had significantly more active compounds than volatiles (Fig. 4). The results indicated that anti-FOC compounds such as 2-methyl-2-pentenal and dimethyl trisulfide are easily released by Chinese chive via leaching and

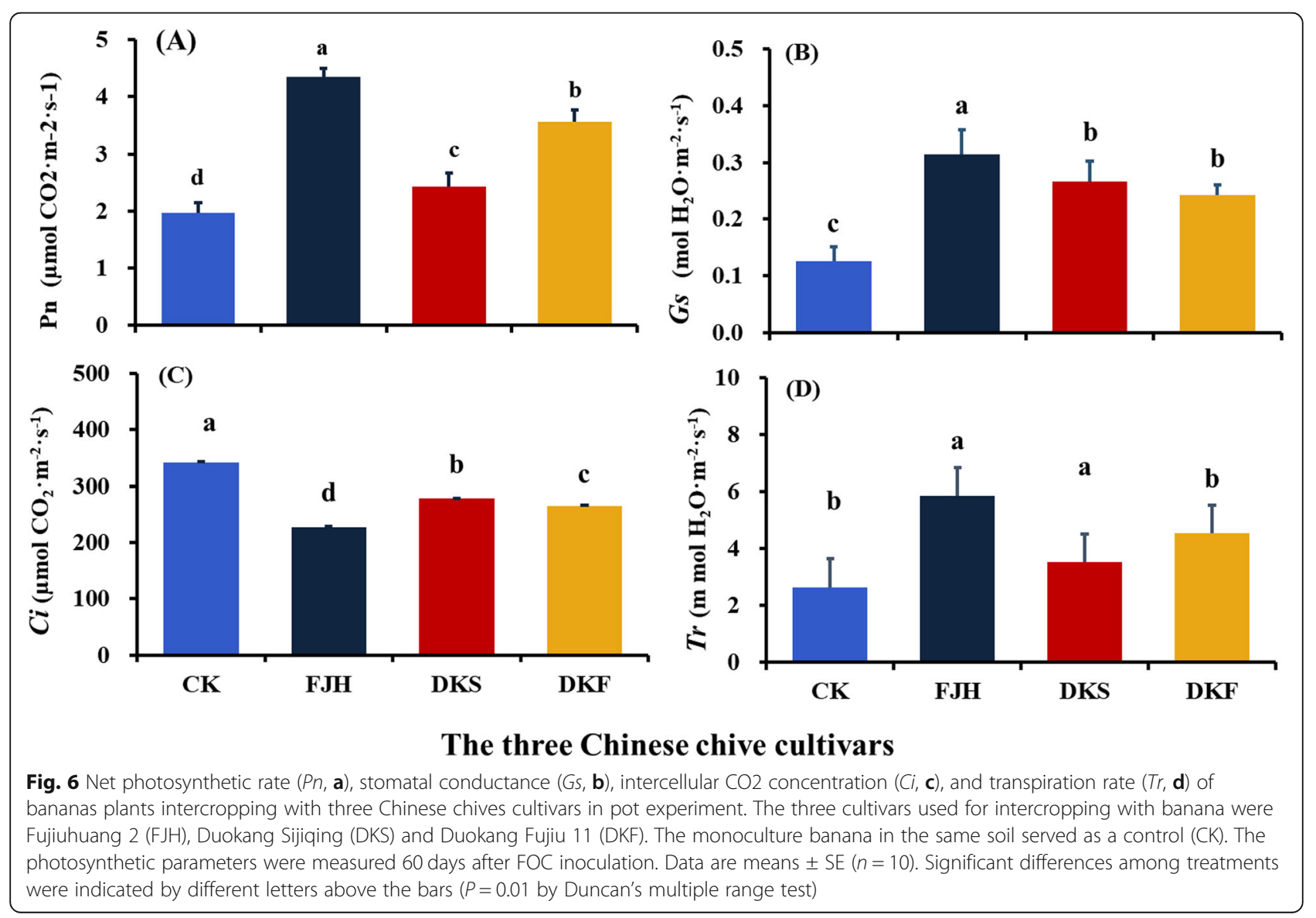




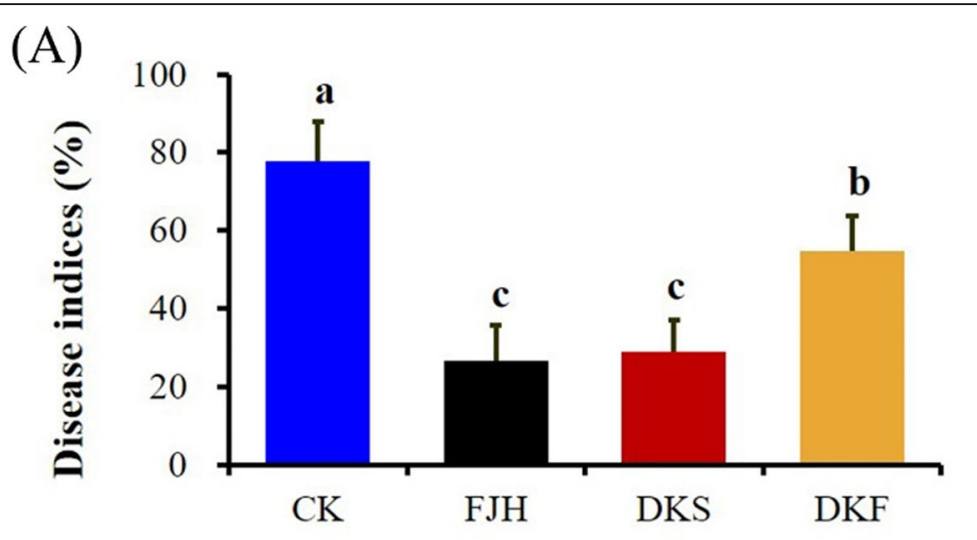

(B)

Chinese chive cultivars
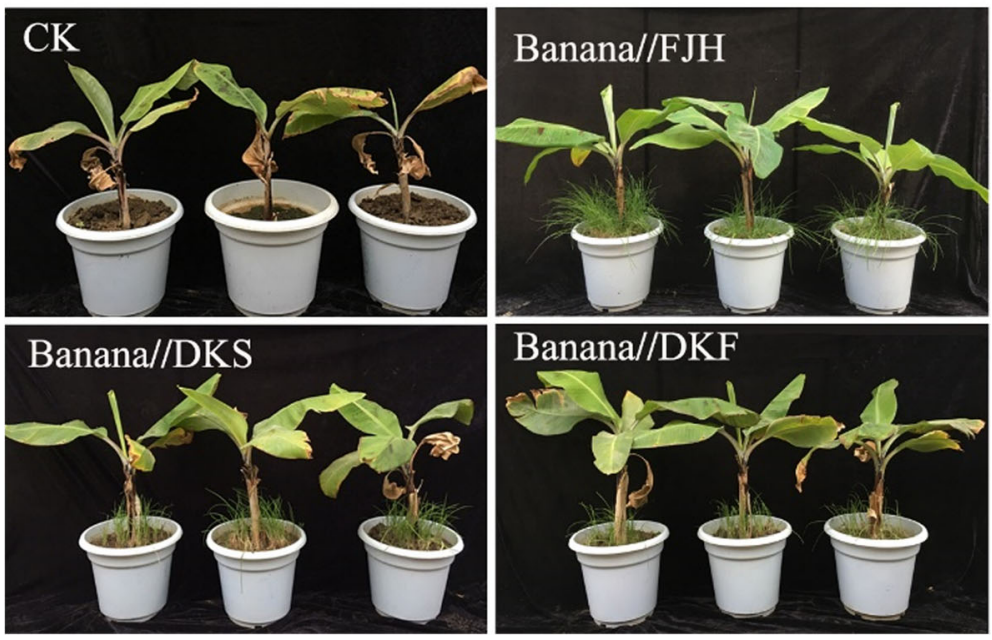

Fig. 7 Fusarium wilt disease incidence (a) and growth performance (b) of banana plants 60 days after inoculation with of Fusarium oxysporum $\mathrm{f}$. sp. cubense race 4 (FOC) in monoculture and intercropping with three Chinese chive cultivars in the pots. The three cultivars used for intercropping with banana were Fujiuhuang 2 (FJH), Duokang Sijiqing (DKS) and Duokang Fujiu 11 (DKF). The monoculture banana in the same soil served as a control (CK). Data are means \pm SE $(n=10)$. Significant differences among treatments were indicated by different letters above the bars ( $P=0.01$ by Duncan's multiple range test)

root exudation. Lian et al. [46] demonstrated that the aqueous leachates of Chinese chive roots were more inhibitory to FOC than those of stems and leaves. Zhang et al. [34] revealed that volatiles excluded by roots of Chinese chive inhibited spore germination of FOC. It is likely that in the field most active compounds of Chinese chive are released into the rhizospheres and then these volatiles spread into the soils to exhibit anti-FOC activity.

Volatile sulfur compounds have been demonstrated to be inhibitory to Fusarium and other pathogenic fungi [47]. Non-sulfur-containing compound 2-methyl-2-pentenal, a degradation product of thiopropanal S-oxide [48], displayed the strongest anti-FOC activity (Fig. 4). The chemical was also found in the onion (Allium cepa L.) essential oil and displayed antifungal activity to $F u$ sarium [47].
Anti-FOC activity and contents of 2-methyl-2-pentenal in the volatiles and aqueous leachates may serve as two desired parameters for preliminary selection of appropriate cultivars of Chinese chive for intercropping with banana.

\section{Conclusion}

Panama disease (Fusarium wilt disease) caused by F. oxysporum f. sp. cubense race 4 (FOC) severely threatens banana (Musa spp.) production worldwide. Intercropping of banana with Chinese chive can effectively reduce Panama disease.

Our study demonstrates that banana intercropping with Chinese chive can effectively reduce Panama disease and selection of appropriate cultivars of Chinese chive for intercropping is key for the success. The six 

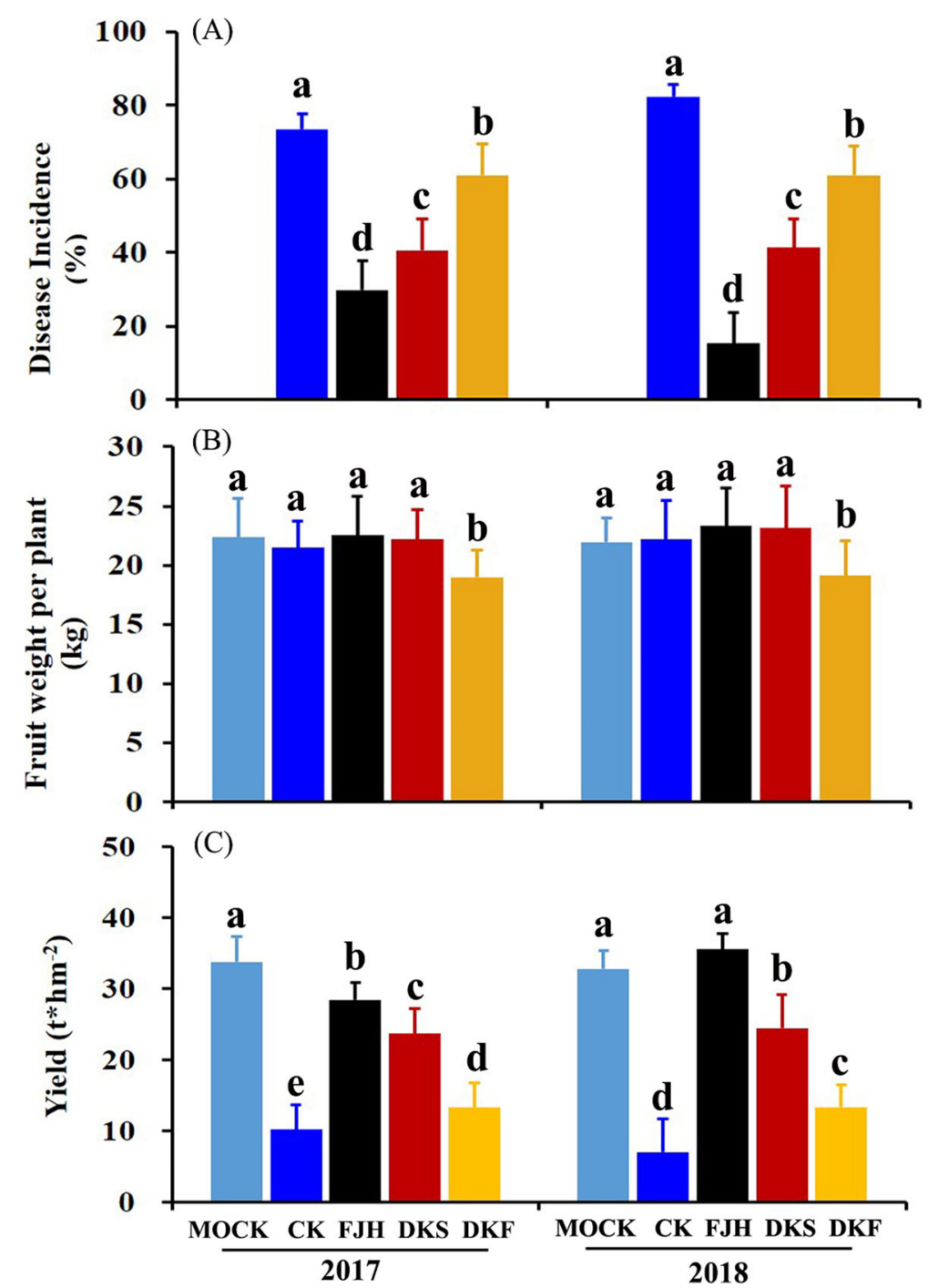

Fig. 8 Fusarium wilt disease incidence (a), fruit weight (b) and yield (c) of banana plants after FOC inoculation in monoculture and intercropping with three Chinese chive cultivars in the field. The three cultivars used for intercropping with banana were Fujiuhuang 2 (FJH), Duokang Sijiqing (DKS) and Duokang Fujiu 11 (DKF). The monoculture banana in the same soil served as a control (CK). Another field nearby with no fusarium wilts disease occurred were also mono-cultured with banana plants (mock). Data are means \pm SE $(n=5)$. Significant differences among treatments were indicated by different letters above the bars $(P=0.01$ by Duncan's multiple range test)

cultivars showed significant differences in antifungal activity against FOC mycelia growth in both leaf volatiles and aqueous leachates. Pot and field experiments showed that intercropping with three selected Chinese chive cultivars significantly improved banana vegetative growth, increased photosynthetic characteristics and yield but decreased disease incidence of Panama disease. Among the six cultivars used FJH and DKS are the most suitable cultivars for intercropping.

\section{Abbreviations}

CK: Control; DKF: Duokang fujiu 11; DKS: Duokang sijiqing; DMT: Dimethyl trisulfide; DPT: Dipropyl trisulfide; FJB: Fujiubao; FJH: Fujiuhuang 2; FOC: Fusarium oxysporum f. sp. cubense race 4; FTJ: Futaijiu 1; Gs: Stomatal conductance; MP: 2-Methyl-2-pentenal; PDA: Potato dextrose agar; Pn: Net photosynthetic rate; SE: Standard error; Tr: Transpiration rate; ZGC: Zigenchun zaohong

\section{Acknowledgments \\ Not applicable.}

\section{Authors' contributions}

$Z F, R S$, and $Y Y$ conceived and designed the experiments and wrote the manuscript; ZF, TW, CL and KL carried out the experiments and analyzed data; All authors revised the manuscript. All authors read and approved the final manuscript.

\section{Funding}

This research was supported by the Natural Science Foundation of Fujian Province of China (2019 J01657, 2019 J01375), Science and Technology Innovation Special Fund Project of Fujian Agriculture and Forestry University (CXZX2016162). The funding provided the financial support to the research 
programs, but didn't involve in work design, data collection, analysis and preparation of the manuscript.

\section{Availability of data and materials}

All data generated or analysed during this study are included in this published article.

\section{Ethics approval and consent to participate}

Not applicable.

\section{Consent for publication}

The authors declare agree that the articles published in BMC plant biology.

\section{Competing interests}

The authors declare that they have no competing interests.

Received: 7 May 2020 Accepted: 8 September 2020

Published online: 17 September 2020

\section{References}

1. Li WB, Wang XL, Li CQ, Sun JB, Li SX, Peng M (2019) Dual species transcript profiling during the interaction between banana (Musa acuminata) and the fungal pathogen Fusarium oxysporum f. sp. cubense. BMC Genomics 20:519534. https://doi.org/https://doi.org/10.1186/s12864-019-5902-z.

2. Singh B, Singh JP, Kaur A, Singh N (2016) Bioactive compounds in banana and their associated health benefits - a review. Food Chem 206: 1-11. https://doi.org/https://doi.org/10.1016/j.foodchem.2016.03.033.

3. Paul JY, Khanna H, Kleidon J, Hoang P, Geijskes J, Daniells J, Zaplin E, Rosenberg E, James A, Mlalazi B, Deo P, Arinaitwe G, Namanya P, Becker D, Tindamanyire J, Tushemereirwe W, Harding R, Dale J (2017) Golden bananas in the field: elevated fruit pro-vitamin a from the expression of a single banana transgene. Plant Biotechnol J 5: 520-532. https://doi.org/https://doi. org/10.1111/pbi.12650

4. Segura RA, Stoorvogel JJ, Samuels JZ, and Sandoval JA (2018) Managing the interactions between soil abiotic factors to alleviate the effect of Fusarium wilt in bananas. Acta Hortic 1196: 163-168. https://doi.org/https://doi.org/ 10.17660/actahortic.2018.1196.19.

5. Dong HH, Fan HY, Lei ZX, Wu C, Zhou DB, Li HP (2019) Histological and gene expression analyses in banana reveals the pathogenic differences between races 1 and 4 of banana Fusarium wilt pathogen. Phytopathology 109: 1029-1042. https://doi.org/https://doi.org/10.1094/phyto-10-18-0384-r.

6. Ploetz RC (2015) Management of Fusarium wilt of banana: a review with special reference to tropical race 4. Crop Prot 73: 7-15. https://doi.org/ https://doi.org/10.1016/j.cropro.2015.01.007.

7. Xue C, Penton CR, Shen ZZ, Zhang RF, Huang QW, Li R, Ruan YZ, Shen QR (2015) Manipulating the banana rhizosphere microbiome for biological control of Panama disease. Sci Rep 5: e11124. https://doi.org/https://doi.org/ 10.1038/srep11124.

8. Butler D (2013) Fungus threatens top banana. Nature 504: 195-196. https:// doi.org/https://doi.org/10.1038/nmiddleeast.2013.241.

9. Shen ZZ, Ruan YZ, Chao X, Zhang J, Li R, Shen QR (2015) Rhizosphere microbial community manipulated by 2 years of consecutive biofertilizer application associated with banana Fusarium wilt disease suppression. Biol Fertil Soils 51: 553-562. https://doi.org/https://doi.org/10.1007/ s00374-015-1002-7.

10. Shen ZZ, Xue C, Taylor PWJ, Ou YN, Wang BB, Zhao Y, Ruan YZ, Li R, Shen $\mathrm{QR}$, (2018) Soil pre-fumigation could effectively improve the disease suppressiveness of biofertilizer to banana Fusarium wilt disease by reshaping the soil microbiome. Biol Fertil Soils 54: 793-806. https://doi.org/ https://doi.org/10.1007/s00374-018-1303-8

11. Fu L, Penton CR, Ruan Y, Shen Z, Xue C, Li R, Shen Q (2017) Inducing the rhizosphere microbiome by biofertilizer application to suppress banana Fusarium wilt disease. Soil Biol Biochem 104: 39-48. https://doi.org/https:// doi.org/10.1016/j.soilbio.2016.10.008

12. Sun L, Song S, Fu L, Deng XH, Wang DS, Liang XL, Li R, Shen QR (2015) Exploring a soil fumigation strategy based on ammonium bicarbonate to control Fusarium wilts of cucurbits. Crop Prot 70: 53-60. https://doi.org/ https://doi.org/10.1016/j.cropro.2015.01.004.

13. Xiong W, Li R, Ren Y, Liu C, Zhao Q, Wu H, Jousset A, Shen Q (2017) Distinct roles for soil fungal and bacterial communities associated with the suppression of vanilla Fusarium wilt disease. Soil Biol Biochem 107: 198-207. https://doi.org/https://doi.org/10.1016/j.soilbio.2017.01.010.

14. Shen ZZ, Zhong ST, Wang YG, Wang BB, Mei XL, Li R, Ruan YZ, Shen QR (2013) Induced soil microbial suppression of banana fusarium wilt disease using compost and biofertilizers to improve yield and quality. Eur J Soil Biol 57: 1-8. https://doi.org/https://doi.org/10.1016/j.ejsobi.2013.03.006.

15. Wei YX, Liu W, Hu W, Liu GY, Wu CJ, Liu W, Zeng HQ, He CZ, Shi HT (2017) Genome-wide analysis of autophagy-related genes in banana highlights MaATG8s in cell death and autophagy in immune response to Fusarium wilt. Plant Cell Rep 36, 1237-1250. https://doi.org/https://doi.org/10.1007/ s00299-017-2149-5.

16. Pattison AB, Molina AB, Chao CP, Viljoen A, Lindsay SJ (2018) Integrating management practices to support banana production in the presence of Fusarium wilt. Acta Hortic 1196: 129-135. https://doi.org/https://doi.org/10. 17660/actahortic.2018.1196.15.

17. Trivedi P, Delgado-Baquerizo M, Trivedi C, Hamontsb K, Anderson IC, Singhbd BK (2017) Keystone microbial taxa regulate the invasion of a fungal pathogen in agro-ecosystems. Soil Biol Biochem 111: 10-14. https://doi.org/ https://doi.org/10.1016/j.soilbio.2017.03.013.

18. Han GY, Lang J, Sun Y, Wang YY, Zhu YY, Lu BR (2016) Intercropping of rice varieties increases the efficiency of blast control through reduced disease occurrence and variability. J Integr Agric 15: 795-802. https://doi.org/https:// doi.org/10.1016/s2095-3119(15)61055-3.

19. Yu HJ, Chen SC, Zhang XX, Zhou XG, Wu FZ (2019) Rhizosphere bacterial community in watermelon-wheat intercropping was more stable than in watermelon monoculture system under Fusarium oxysporum f. sp. niveum invasion. Plant Soil 445: 369-381. https://doi.org/10.1007/s11104-019-04321-5.

20. Li XG, Boer WD, Zhang YN, Ding CF, Zhang TL, \& Wang XX (2018) Suppression of soil-borne Fusarium pathogens of peanut by intercropping with the medicinal herb Atractylodes lancea. Soil Biol Biochem 116: 120-130. https://doi.org/https://doi.org/10.1016/j.soilbio.2017.09.029.

21. Yu JQ. Allelopathic suppression of pseudomonas solanacearum infection of tomato (Lycopersicon esculentum) in a tomato-Chinese chive (Allium tuberosum) intercropping system. J Chem Ecol. 1999;25:2409-17.

22. Benkeblia N (2004) Antimicrobial activity of essential oil extracts of various onions (Allium cepa) and garlic (Allium sativum). LWT-Food Sci Technol 37: 263-268. https://doi.org/https://doi.org/10.1016/j.lwt.2003.09.001.

23. Liaqat A, Zahoor T, Randhawa MA, Shahid M (2019) Characterization and antimicrobial potential of bioactive components of sonicated extract from garlic (Allium sativum) against foodborne pathogens. J Food Process Preservation 43: e13936. https://doi.org/https://doi.org/10.1111/jfpp.13936.

24. Sharifi-Rad J, Mnayer D, Tabanelli G, Stojanović-radić DD, Sharifi-Rad M, Yousaf Z, Vallone L, Setzer WN, Iriti M (2016) Plants of the genus Allium as antibacterial agents: from tradition to pharmacy. Cell Mol Biol 62: 57-68. https://doi.org/https://doi.org/10.1016/j.foodchem.2014.10.042.

25. Mnayer D, Fabiano-Tixier AS, Petitcolas E, Hamieh T, Nehme N, Ferrant C, Fernandez X, Chemat F (2014) Chemical composition, antibacterial and antioxidant activities of six essentials oils from the Alliaceae Family. Molecules 19: 20034-20053. https://doi.org/10.3390/molecules191220034.

26. Gao Q, Li XB, Sun J, Xia ED, Tang F, Cao HQ, Xun H (2018) Isolation and identification of new chemical constituents from Chinese chive (Allium tuberosum) and toxicological evaluation of raw and cooked Chinese chive. Food Chem Toxicol 112: 400-411. https://doi.org/https://doi.org/10.1016/j. fct.2017.02.011.

27. Hu G, Mao R, Ma Z (2009) A new steroidal saponin from the seeds of Allium tuberosum. Food Chem 113: 1066-1068. https://doi.org/https://doi.org/10. 1016/.foodchem.2008.08.061.

28. Jannat K, Rahman T, Rahmatullah M. Traditional uses, phytochemicals and pharmacological properties of Allium tuberosum Rottler ex spreng. J Med Plants Stud. 2019:7:214-20.

29. Katarzyna AS, Joanna T (2016) Yielding and biological value of garlic chives (Allium tuberosum Rottl. Ex Spreng.) depending on the type of mulch. J Elem 21: 7-9. https://doi.org/https://doi.org/10.5601/jelem.2015.20.2.910.

30. Zuo GW, Li CY, Li B, Wei YR, Hu CH, Yang QS, Yang J, Sheng O, Kuang RB, Deng GM, Biswas MK, Yi GJ (2015) The toxic mechanism and bioactive components of Chinese leek root exudates acting against Fusarium oxysporum f. sp. cubense, tropical race 4. Eur J Plant Pathol 143: 447-460. https://doi.org/https://doi.org/10.1007/s10658-015-0697-5.

31. Huang YH, Wang RC, Li CH, Zuo CW, Wei YR, Zhang L, \& Yi GJ (2012) Control of Fusarium wilt in banana with Chinese leek. Eur J Plant Pathol 134: 87-95. https://doi.org/https://doi.org/10.1007/s10658-012-0024-3. 
32. Lanzotti V, Scala F, \& Bonanomi G (2014) Compounds from Allium species with cytotoxic and antimicrobial activity. Phytochem Rev 13: 769-791. https://doi.org/https://doi.org/10.1007/s11101-014-9366-0.

33. Dania VO, Omidiora JA (2019) Combination of biological control agents and garlic (Allium sativum) extract in reducing damping-off disease of tomato. Bangladesh J Agric Res 44: 553-567. https://doi.org/https://doi.org/10.3329/ bjar.v44i3.43485

34. Zhang H, Mallik A, Zeng R (2013) Control of Panama disease of banana by rotating and intercropping with Chinese chive ( Allium tuberosum Rottler): role of plant volatiles. J Chem Ecol 39: 243-252. https://doi.org/https://doi. org/10.1007/s10886-013-0243-x

35. Wibowo A, Alboneh AR, Somala MUA, Subandiyah S, Pattison T, Molina A (2015) Increasing soil suppressivity to Fusarium wilt of banana through banana intercropping with Allium spp. J Perlindungan Tanaman Indones 19: 33-39. https://doi.org/https://doi.org/10.22146/jpti.16344.

36. Soni B, Tseng TMP, Yue ZM (2019) Identification and quantification of allelochemicals from selected sweet potato (Ipomoea batatas (L.) lam.) cultivars. Am J Plant Sci 10: 2354-2365. https://doi.org/https://doi.org/10. 4236/ajps.2019.1012163.

37. Sun JM, Zhang JZ, Fang H, Peng L, Wei SL, Li HS, Zheng SJ, Lu J (2019) Comparative transcriptome analysis reveals resistance-related genes and pathways in Musa acuminata banana 'Guijiao 9 ' in response to Fusarium wilt. Plant Physiol Biochem 141: 83-94. https://doi.org/https://doi.org/10. 1016/j.plaphy.2019.05.022.

38. Nandakumar R, Eyrs G, Burritt DJ, Kebede B, Leus M, Oey I (2018) Impact of pulsed electric fields on the volatile compounds produced in whole onions (Allium cepa and Allium fistulosum). Foods 7: 183-189. https://doi.org/ https://doi.org/10.3390/foods7110183.

39. Cheng CZ, Li D, Qi Q, Sun XL, Anue MR, David BM, Zhang YY, Hao XG, Zhang ZH, Lai ZX (2020) The root endophytic fungus Serendipita indica improves resistance of banana to Fusarium oxysporum f. sp. cubense tropical race 4. Eur J Plant Pathol 156: 87-100. https://doi.org/https://doi.org/10. 1007/s10658-019-01863-3.

40. Shen Z, Xue C, Penton CR, Thomashow LS, Zhang N, Wang B, Shen Q (2019) Suppression of banana Panama disease induced by soil microbiome reconstruction through an integrated agricultural strategy. Soil Biol Biochem 128:164-174. https://doi.org/https://doi.org/10.1016/j. soilbio.2018.10.016

41. Wang B, Li R, Ruan Y, Ou Y, Zhao Y, Shen Q (2015) Pineapple-banana rotation reduced the amount of Fusarium oxysporum more than maizebanana rotation mainly through modulating fungal communities. Soil Biol Biochem 86: 77-86. https://doi.org/https://doi.org/10.1016/j.soilbio.2015.02 021.

42. Schulz H, Krüger H, Liebmann J, Peterka H (1998) Distribution of volatile sulfur compounds in an interspecific hybrid between onion (Allium cepa L.) and leek (Allium porrum L.). J Agric Food Chem 46: 5220-5224. https://doi. org/https://doi.org/10.1021/jf9806208.

43. Hammerbacher A, Coutinho TA, Gershenzon J (2019) Roles of plant volatiles in defense against microbial pathogens and microbial exploitation of volatiles. Plant Cell Environ 42: 2827-2843. https://doi.org/https://doi.org/10. 1111/pce.13602.

44. Marrelli M, Amodeo V, Statti G, Conforti F (2019) Biological properties and bioactive components of Allium cepa L.: focus on potential benefits in the treatment of obesity and related comorbidities. Molecules 24: 119-136. https://doi.org/https://doi.org/10.3390/molecules24010119.

45. Ozkan O, Gul S, Kart A, Cicek BA, Kilic K (2013) In vitro antimutagenicity of Allium tuncelianum ethanol extract against induction of chromosome aberration by mutagenic agentmitomycine C. Kafkas Univ Vet Fakul Derg 19: 259-262. https://doi.org/https://doi.org/10.9775/kvfd. 2012.7637.

46. Lian FZ, Xue RR, Lin XH, Yang YR, Zhang H, Zeng RR, Song YY. Inhibitory effects of aqueous leachates and volatiles from Allium tuberosum and Ageratum conyzoides on Fusarium oxysporum f. sp. Cubense. J S China Agric Univ. 2019;40:40-6 (In Chinese)

47. Kocić-Tanackov S, Dimić G, Mojović L, Gvozdanović-Varga J, Djukić-Vuković A, Tomović V, \& Pejin J (2017) Antifungal activity of the onion (Allium cepa L.) essential oil against Aspergillus, Fusarium and Penicillium species isolated from food. J Food Process Preservation 41: e13050. https://doi.org/https:// doi.org/10.1111/jfpp.13050.

48. Ferary S, Auger J (1996) What is the true odour of cut Allium? Complementarity of various hyphenated methods: gas chromatography- mass spectrometry and high-performance liquid chromatography-mass spectrometry with particle beam and atmospheric pressure ionization interfaces in sulphenic acids rearrangement components discrimination. J Chromatogr A 750: 63-74. https://doi.org/https://doi.org/10.1016/00219673(96)00405-0.

\section{Publisher's Note}

Springer Nature remains neutral with regard to jurisdictional claims in published maps and institutional affiliations.
Ready to submit your research? Choose BMC and benefit from:

- fast, convenient online submission

- thorough peer review by experienced researchers in your field

- rapid publication on acceptance

- support for research data, including large and complex data types

- gold Open Access which fosters wider collaboration and increased citations

- maximum visibility for your research: over $100 \mathrm{M}$ website views per year

At BMC, research is always in progress.

Learn more biomedcentral.com/submissions 